\title{
Compressive behavior of glulam columns with initial cracks under eccentric loads
}

\author{
Jing Zhang ${ }^{1} \cdot$ Minjuan $\mathrm{He}^{1} \cdot{\text { Zheng } \mathrm{Li}^{1}}^{1}$
}

Received: 29 November 2017 / Accepted: 12 January 2018 / Published online: 25 January 2018

(c) The Author(s) 2018. This article is an open access publication

\begin{abstract}
This paper investigates the mechanical performance of longitudinally cracked glulam columns under eccentric compression loads. Experimental investigation was conducted to explore the influence of initial cracks on the failure modes and load bearing capacity of glulam columns. Two different crack patterns named DC and IC, and two column lengths (i.e. 600 and $1100 \mathrm{~mm}$ ) were considered in the experiments. It was indicated that these two crack patterns reduced the capacity of slender glulam columns and the difference of failure modes was observed between glulam columns with and without initial cracks. Further, a numerical model was developed and validated by the test results. With the application of cohesive zone material model, the propagation of initial cracks could be considered in the numerical modeling. A parametric study was carried out by the verified model and the influence of crack lengths and crack locations was further investigated. From the numerical analysis, it was found that through cracks reduced the capacity of glulam columns significantly. Also, crack location impacts the capacity of glulam columns and the extent of impact relates to the slenderness ratio of the columns, while cracks with different lengths have similar influence on the capacity of columns.
\end{abstract}

Keywords Glulam columns $\cdot$ Eccentric load $\cdot$ Initial cracks $\cdot$ Numerical model

\section{Introduction}

Timber structures are sensitive to the climate variations when exposed to outdoor environment, as wood is a hygroscopic material. With the change of humidity and temperature of the surrounding air, uneven shrinkage or swelling deformation can be formed in the cross section of timber elements, and internal stresses will be further produced (Larsen and Ormarsson 2013). Due to low perpendicular-to-grain tensile strength of wood, longitudinal cracks are frequently observed in timber elements (Frühwald et al. 2007). It was also proved by a previous field experiment, which indicated that when glulam elements were exposed to external climate conditions, moisture-induced stresses would exceed

Zheng Li

zhengli@tongji.edu.cn

Jing Zhang

1991zhangjing@tongji.edu.cn

Minjuan He

hemj@ tongji.edu.cn

1 Department of Structural Engineering, Tongji Univ., 1239 Siping Rd., Shanghai 200092, China the tensile strength of wood in the perpendicular-to-grain direction (Fragiacomo et al. 2011).

To evaluate the influence of cracks on the mechanical performance of timber components with initial cracks, several related researches have been conducted, and the emphasis has been set on glulam beams and steel-to-timber bolted connections. In terms of glulam beams, numerical analysis (Berg et al. 2015; Khorasan 2012; Saracoglu 2011) and experimental investigation (Larsen and Ormarsson 2013; Pousette 2012) have been conducted on the mechanical behavior of glulam beams with cracks. Two different fracture mechanics models have been applied to explore the effect of cracks on the behavior of double-tapered glulam beams (Blyberg 2008). Further, the methods of detecting cracks and the equations for predicting shear strength can be found in several standards (APA-The Engineered Wood Association and Engineered Wood Systems 2006, 2007; AITC-American institute of timber construction 2011). For steel-to-timber bolted connections, previous investigations found that moisture-induced stresses have a detrimental effect on the capacity of bolted connections under tension load (Sjödin 2006, 2008; Sjödin and Johansson 2006; Sjödin et al. 2004, 2006; Sjödin and Serrano 2008). In the case of moment-resisting 
bolted connections, experimental researches have been conducted to investigate the influence of initial cracks, and a theoretical method based on a quasi-non-linear fracture mechanics model has been proposed to predict the capacity of bolted connections with initial cracks (He et al. 2017). For timber columns, a finite-element-method-based model was developed to investigate the effect of cracks on the stiffness and capacity of timber columns under compressive load (He 2016). However, few researches have been conducted to investigate the compressive behavior of glulam columns with initial cracks under eccentric loads.

To estimate the status of timber elements, crack is always a key factor that needs to be considered, and the cracks may propagate along the grain direction, which will reduce the capacity of timber elements and even result in collapse of the whole timber structure. To analyze cracking problems in timber elements, linear elastic fracture mechanics model is first applied in timber engineering. To obtain the fracture parameter, energy release rate at crack tip, J-integral evaluation (Pop et al. 2013) and virtual crack closure technique (De Moura et al. 2006; Yoshihara 2008) have been commonly used in numerical analysis. Mean stress approach is a generalized linear elastic fracture mechanics model, which considers mean stresses acting across a certain area (Gustafsson 2002). It has been applied in the strength analysis of glulam beams with holes (Danielsson and Gustafsson 2011). Fictitious or cohesive crack models are commonly applied to perform nonlinear fracture mechanics modeling in timber structures. The progressive cracking process can be perfectly described by the models. A fracture process zone is assumed ahead of the crack tip, which is considered as a fictitious crack with a constitutive relation to model the cracking behavior (Serrano and Gustafsson 2007). After reaching maximum stress level, the behavior of fracture zone will switch to a softening segment with increasing damage. A bilinear stress-softening model has been applied in the numerical analysis of single-edge-notched timber beams (Dourado et al. 2008). Cohesive zone material model with bilinear traction-separation relationship is commonly applied in the analysis of dowel connections (Franke and Quenneville 2011) and timber elements (Oliveira et al. 2007). Interface elements or contact element pairs have been applied on potential cracking path to simulate crack propagation process (Coureau et al. 2007).

From previous researches conducted on timber columns, it was found that the capacity and ductile performance of timber columns were dramatically decreased due to the existence of initial cracks (He et al. 2016; Zhang et al. 2012). Thus, it is quite prominent to further predict the compressive behavior of glulam columns with initial cracks under eccentric loads. This paper experimentally investigates the influence of cracks on the mechanical performance of eccentrically loaded columns. Two different crack patterns and slenderness ratios of columns are considered in the test. The obtained failure modes and experimental results are presented and analyzed. A finite-element-method-based model was developed with the application of Hill yield criterion and cohesive zone material model was applied to simulate crack propagation. The numerical model was validated by the experimental results and the verified model was applied to conduct a parametric study on the influence of through cracks, which further quantified the influence of different crack lengths and crack locations.

\section{Experimental study}

Full-scale glulam columns were tested under eccentric compression load. Two different column lengths $(600 \mathrm{~mm}$ and $1100 \mathrm{~mm}$, respectively) were considered, and all the specimens with same cross-sectional size (width $60 \times$ depth $90 \mathrm{~mm}$ ) were prepared for the test, as shown in Fig. 1. Same batch of spruce-pine-fir (SPF) lumber with mean moisture content and density of $14.9 \%$ and $230 \mathrm{~kg} / \mathrm{m}^{3}$, respectively, was used to manufacture the glulam columns. The standard deviations of the moisture content and density are $0.9 \%$ and $21 \mathrm{~kg} / \mathrm{m}^{3}$, respectively. Considering the randomly formed cracks in real glulam columns, two different crack patterns were manually made in the specimens. For the crack pattern notated as DC, two initial cracks were set symmetrically about the major axis of the cross-section, and crack depth was along the minor axis with depth ratio of 0.35 , which was defined by dividing crack depth to the column depth. Both cracks were cut from the bottom end to the mid-length of columns. For the crack pattern notated as IC, two initial cracks were set in different lumbers and interacted at the glue line, as shown in Fig. 1c. Also, the cracks were cut from the bottom end to the mid-length of columns. All the cracks are made with a constant width of $3 \mathrm{~mm}$ and sharp crack tips are formed by a thin razor blade at the end of saw cuts. Four replicates are prepared for each configuration of glulam columns. All the specimens were loaded by a hydraulic testing machine and the eccentricity rate was set as 0.25 , which was defined by dividing the eccentricity to the column width. The compressive load was applied at a rate of $6-8 \mathrm{kN} /$ $\mathrm{min}$ and the failure of member attained within 5-10 min. All the members were placed vertically and simply supported along the depth direction of the columns by unidirectional knife-edge hinge supports, as shown in Fig. 1.

For glulam columns without initial cracks, four strain gauges were attached to the four sides of cross section at mid-height of the columns, and the transverse deflection of columns were measured by six linear variable differential transformers (LVDTs), which were set near the both ends and at the mid-height of the glulam columns, as presented in Fig. 1a. For columns with crack pattern DC, six strain gauges 


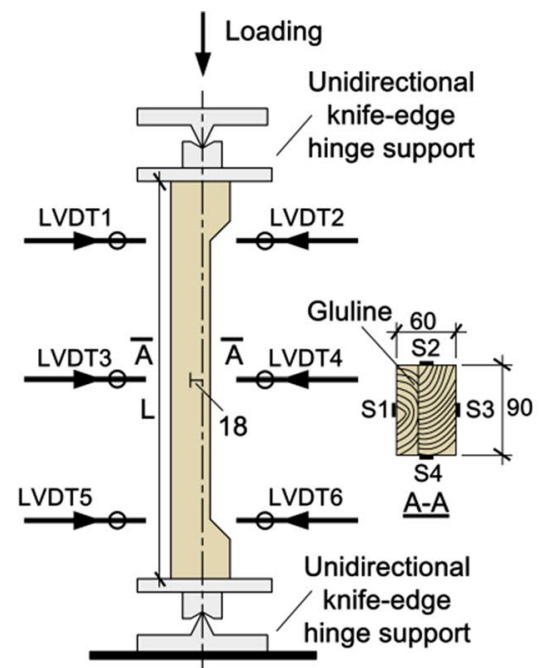

(a)

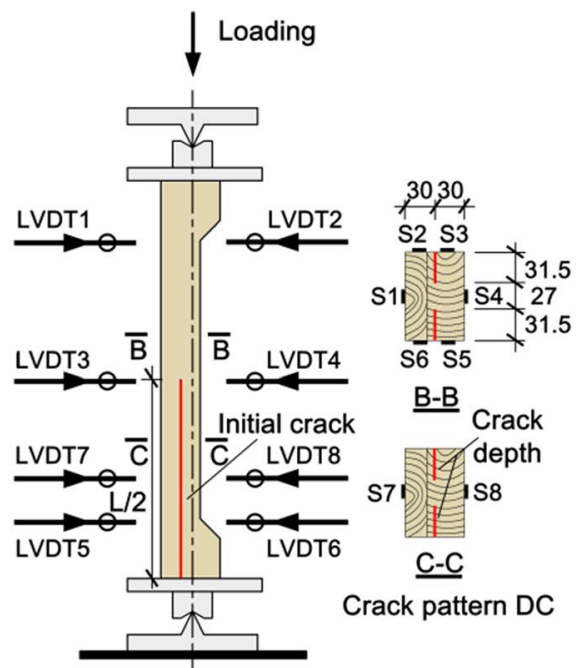

(b)

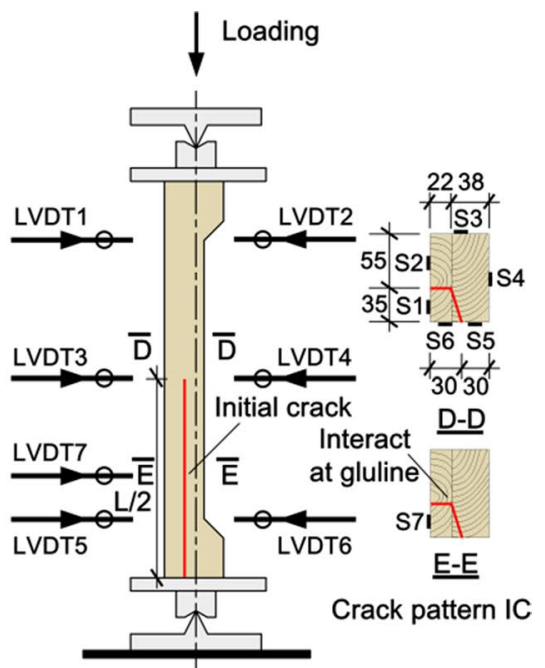

(c)

Fig. 1 The configurations of load setup and layout of LVDTs and strain gauges for glulam columns with different crack patterns: a glulam columns without initial cracks; b glulam columns with crack pattern DC; $\mathbf{c}$ glulam columns with crack pattern IC

were set at the mid-height cross section symmetrically to the crack planes, and two more strain gauges were set on the compression and tension sides at the mid-length of initial cracks. Six LVDTs were set at the same positions as initially perfect columns, and two more LVDTs were attached to the mid-length of initial cracks, as shown in Fig. 1b. For columns with crack pattern IC, six strain gauges were set at the mid-height cross section, and one more strain gauge was set on the mid-length cross section of the small branch formed by initial cracks. In terms of the layouts of LVDTs, one more LVDT7 was attached to the mid-length of the small branch, which was the only difference from columns without initial cracks, as shown in Fig. 1c.

\section{Results and discussion}

The failure modes of different configurations of glulam columns are presented in Fig. 2. For columns with length of $600 \mathrm{~mm}$, typical crushing failure was observed in columns without initial cracks, as shown in Fig. 2a. For columns with crack pattern DC, the propagation of initial cracks was observed at the end of loading process and a through crack was formed, as shown in Fig. 2b. The specimen experienced crushing failure near the mid-height part. For glulam columns with crack pattern IC, the small branch formed by initial cracks was separated from the main branch due to the crack opening, and crushing failure was observed near the center part, as presented in Fig. 2c. For glulam columns with length of $1100 \mathrm{~mm}$, buckling failure and significant lateral deflection near the mid-height were observed in initially perfect columns, as shown in Fig. 2d. For columns with crack pattern DC, a crack through the whole cross section was formed, which is similar to the corresponding case of columns with length of $600 \mathrm{~mm}$. The crack propagation along the grain direction was observed, and the branch on the compressive side exhibited crushing failure near the midlength of initial cracks, as presented in Fig. 2e. For columns with crack pattern IC, the crushing failure near the midlength of initial cracks was observed in the main branch, while no obvious damage was found in the small branch, as shown in Fig. 2f.

The relationships between compressive load and lateral deflection or longitudinal strain of glulam columns are presented in Fig. 3. In the format legend A-B-C-D, A indicates the column length including two different values (i.e. 600 and $1100 \mathrm{~mm}$, respectively), B represents the crack pattern included in columns, where NO stands for columns without initial cracks and DC and IC represent the crack pattern DC and IC, respectively, $\mathrm{C}$ indicates the locations of measuring point for the data in horizontal axis of this figure, where ML and CML represent the data measured at mid-height of columns and mid-length of initial cracks, respectively, and SBML represents the data detected at mid-length of the small branch in columns with crack pattern IC, which is obtained by LVDT 7 and strain gauge S7, as shown in Fig. 1 . And D, only defined in Fig. 3b, d, represents the longitudinal strains measured in tensile or compressive side of the cross section. As shown in Fig. 3a, crack pattern IC reduces the capacity of columns with length of $600 \mathrm{~mm}$ by around $10 \%$. In Fig. 3b, it can be seen that the tensile strain measured at the mid-length of the small branch in columns with crack pattern IC, which is denoted as 600-IC-SBML-Tensile, decreases to zero when the applied load is close to the peak 
Fig. 2 The failure modes of glulam columns under eccentric compression load: a initially perfect glulam columns with length of $600 \mathrm{~mm}$; $\mathbf{b}$ glulam columns with length of $600 \mathrm{~mm}$ and crack pattern DC; $\mathbf{c}$ glulam columns with length of $600 \mathrm{~mm}$ and crack pattern IC; $\mathbf{d}$ initially perfect glulam columns with length of $1100 \mathrm{~mm}$; e glulam columns with length of $1100 \mathrm{~mm}$ and crack pattern DC; f glulam columns with length of $1100 \mathrm{~mm}$ and crack pattern IC

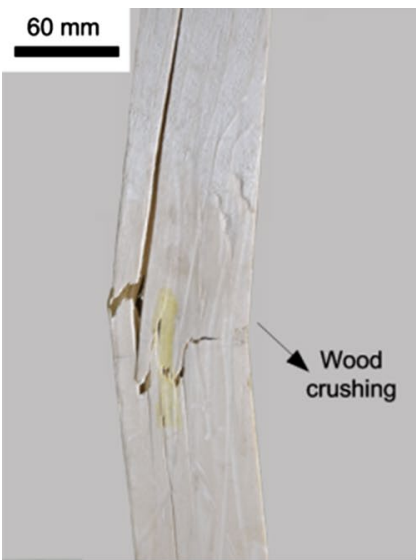

(a)

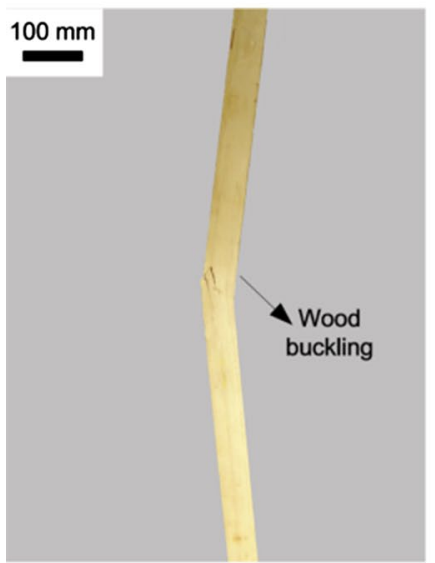

(d)

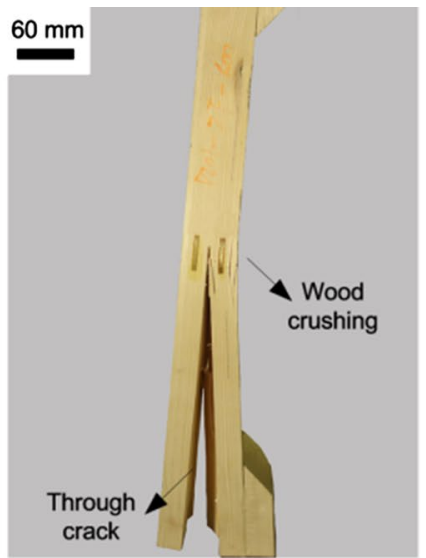

(b)

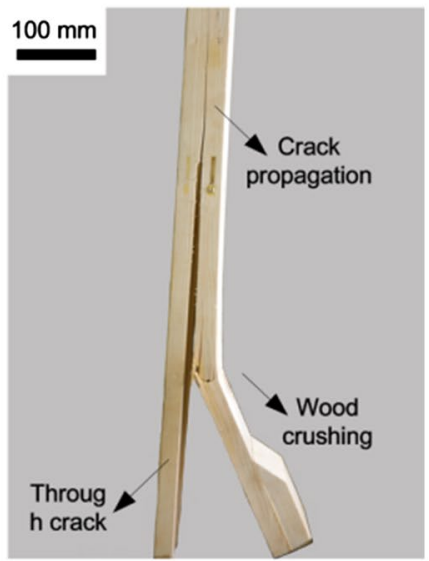

(e)

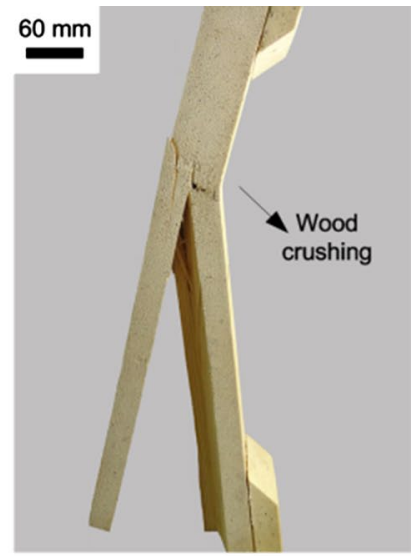

(c)

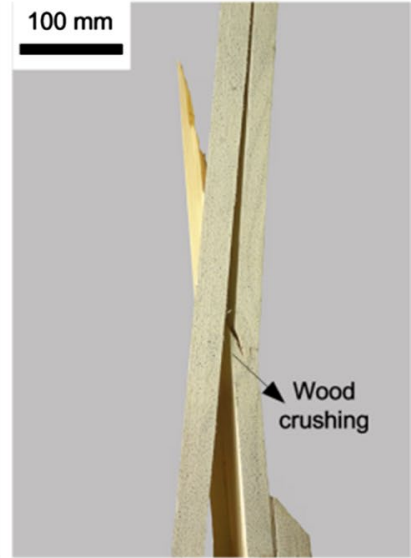

(f) capacity of the column. It indicates that the small branch relieves the load in the later loading stage, which fits well with the experimental observation that the contact interfaces between the small branch and the bottom steel plate separated with each other, as shown in Fig. 2c. For columns with length of $1100 \mathrm{~mm}$, its capacity was reduced by up to $16.6 \%$ due to the existence of crack pattern IC. The capacity of columns with crack pattern DC is $9.9 \%$ lower than that of initially perfect columns, and the lateral deflection at peak point is much less significant than that of columns without initial cracks. Similar to columns with length of $600 \mathrm{~mm}$, unloading is observed in the small branch of columns with crack pattern IC at the end of loading process, as can be seen in Fig. 3d.

\section{Model verification and parametric study}

A numerical model was developed based on commercial software package ANSYS. In the model, structural solid elements SOLID185 and SOLID45 were used to mesh wood and steel plate, respectively. Contact pairs were defined to simulate the interaction between timber specimen and steel plate. Timber is considered to be a transversely orthotropic material, which has equal mechanical properties in radial and tangential directions. The Young's modulus and shear modulus were given as $E_{\mathrm{L}}=11,000 \mathrm{MPa}, E_{\mathrm{T}}=E_{\mathrm{R}}=510 \mathrm{MPa}$, $G_{\mathrm{LT}}=G_{\mathrm{LR}}=845 \mathrm{MPa}$ and $G_{\mathrm{RT}}=80 \mathrm{MPa}$. Poisson's ratios were set as $v_{\mathrm{LT}}=v_{\mathrm{LR}}=0.37$ and $v_{\mathrm{RT}}=0.44$. An isotropic material with $\mathrm{E}=210,000 \mathrm{MPa}$ and $v=0.3$ was defined for steel. Considering the relatively plastic behavior of 


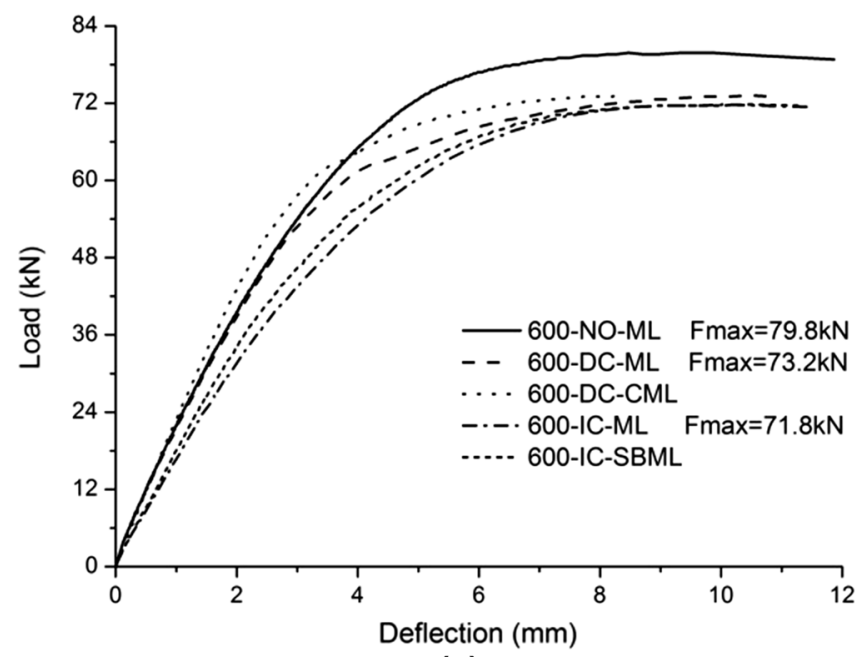

(a)

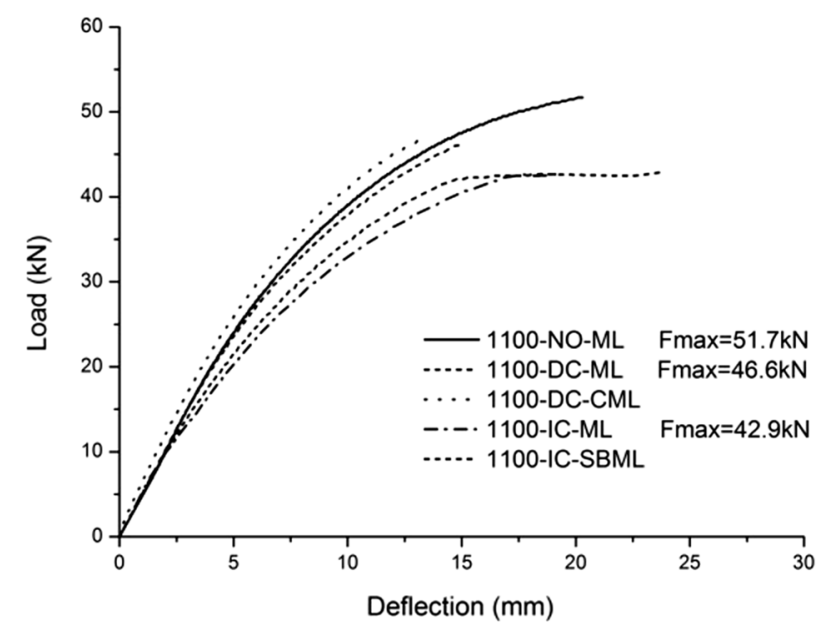

(c)

Fig. 3 The relationships between compressive load and lateral deflection or longitudinal strain of glulam columns: a load and lateral deflection of glulam columns with length of $600 \mathrm{~mm}$; $\mathbf{b}$ load and lon-

wood in compression, a bilinear stress-strain relationship was defined and Hill yield criterion was applied, which was expressed as follows:

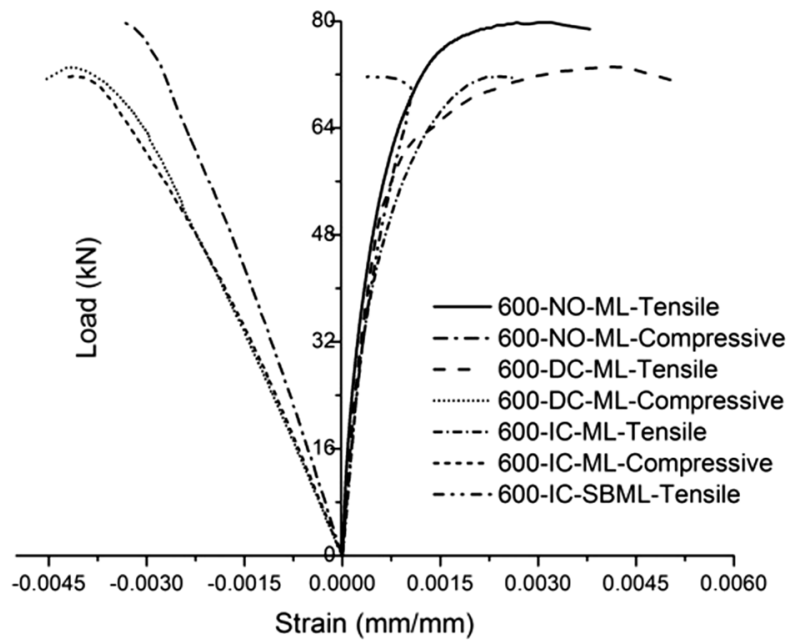

(b)

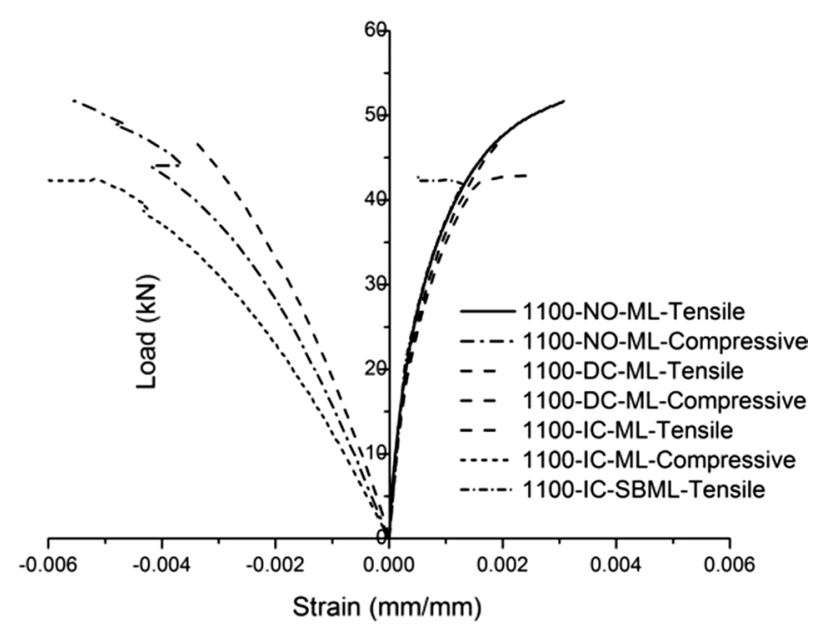

(d)

gitudinal strain of glulam columns with length of $600 \mathrm{~mm}$; $\mathbf{c}$ load and lateral deflection of glulam columns with length of $1100 \mathrm{~mm}$; d load and longitudinal strain of glulam columns with length of $1100 \mathrm{~mm}$

For glulam columns with crack pattern DC, to consider the propagation of initial cracks along the grain and depth directions, cohesive zone material model was used in the

$f\left(\sigma, \sigma_{y}\right)=a_{1}\left(\sigma_{22}-\sigma_{33}\right)^{2}+a_{2}\left(\sigma_{33}-\sigma_{11}\right)^{2}+a_{3}\left(\sigma_{11}-\sigma_{22}\right)^{2}+2 a_{4} \tau_{23}^{2}+2 a_{5} \tau_{31}^{2}+2 a_{6} \tau_{12}^{2}-\sigma_{y}^{2}=0$

$a_{1}=\left(\frac{\sigma_{y}}{\sigma_{22}^{y}}\right)^{2}-\frac{1}{2}\left(\frac{\sigma_{y}}{\sigma_{11}^{y}}\right)^{2} ; \quad a_{2}=a_{3}=\frac{1}{2}\left(\frac{\sigma_{y}}{\sigma_{11}^{y}}\right)^{2} ; a_{4}=\frac{1}{2}\left(\frac{\sigma_{y}}{\sigma_{23}^{y}}\right)^{2} ; \quad a_{5}=a_{6}=\frac{1}{2}\left(\frac{\sigma_{y}}{\sigma_{12}^{y}}\right)^{2}$,

where $\sigma_{i}^{y}$ is yielding stress in the direction denoted by subscript $i . \sigma_{11}^{y}$ and $\sigma_{22}^{y}$ are taken as 32.6 and $3.7 \mathrm{MPa}$, respectively; $\sigma_{12}^{y}$ and $\sigma_{23}^{y}$ are set as 5.7 and $0.6 \mathrm{MPa}$, respectively. The equivalent yield stress $\sigma_{y}$ is an input parameter, taken as compressive strength parallel to the grain $32.6 \mathrm{MPa}$. numerical analysis. A fracture process zone was assumed ahead of crack tip in the model. All fracture mechanisms were assumed to localize and accumulate in this zone, and a constitutive relationship was applied in this fracture process zone to simulate the fracture performance. A linearelastic relation was assumed up to the material strength 
values. When the maximum stress level was attained, all fracture mechanisms would localize in fracture layers and all further deformation would occur in the layers. Increasing deformation in fracture zone would lead to increased damage and declining stress, i.e. softening behavior. In this model, contact element pairs with bilinear traction-separation behavior were defined and applied on potential cracking path to simulate crack propagation process. The interaction of the contact pairs represents the properties of cracking process zone. A combined energy criterion was defined to judge the complete failure of the bond between the contact pairs, which was expressed as follows:

$\frac{G_{I}}{G_{c}^{I}}+\frac{G_{I I}}{G_{c}^{I I}}=1$,

where $G_{I}$ and $G_{I I}$ indicate the fracture energies in the normal and tangential direction, respectively; $G_{c}^{I}$ and $G_{c}^{I I}$ represent the normal and tangential critical fracture energies, taken as 240 and $545 \mathrm{~N} / \mathrm{mm}$, respectively.

In the numerical modeling, it was assumed that the initial imperfection of columns was in proportion to buckling mode shape, which was derived from an eigenvalue analysis. The amplitude of initial imperfection is set as $0.1 \%$ of column length. To verify the results obtained from numerical analysis, a comparison of longitudinal tensile strain in the mid-height of columns was conducted between the experimental values and numerical results. As can be seen from Fig. 4, the models predict well in terms of the development of longitudinal strains and the peak load-carrying capacity of the columns. Variable material properties and the quality

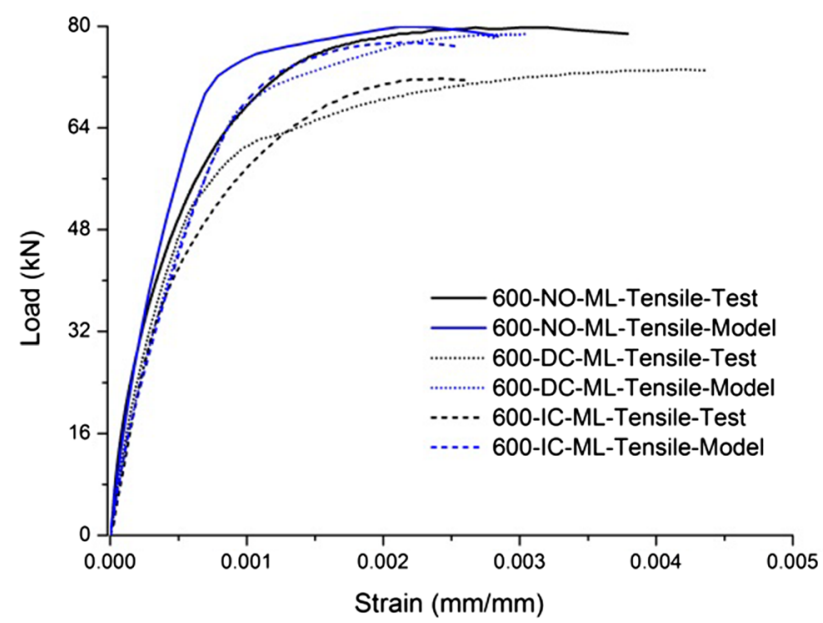

(a)

Fig. 4 The relationships between compressive load and longitudinal strain in the mid-height of glulam columns obtained from experiments and numerical analysis: a load and longitudinal strain of glu- of test specimens are believed to account for the limited discrepancy in the stiffness and capacity. As can be seen from the experimental and numerical results, crack pattern DC has less significant influence on the mechanical behavior of glulam columns. The propagation of initial cracks always occurs simultaneously with the final crushing failure according to the experimental observations, and the glulam columns could bear the compressive load as a whole before the crack propagation. In order to investigate the influence of a through crack on the performance of glulam columns, a parametric study was conducted on glulam columns under eccentric compression load and different crack lengths and crack locations are considered in the analysis. Further, for glulam columns with crack pattern IC, the influence of different crack lengths was investigated by the numerical model. The configurations of glulam columns with through crack or crack pattern IC are shown in Fig. 5. As can be seen from the figure, glulam columns with three different column lengths $(600,850$ and $1100 \mathrm{~mm}$, respectively) are analyzed in the parametric study. Two different crack length ratios ( 0.5 and 0.7 , respectively) are considered in the analysis. For columns with through crack, the locations of cracks in the width direction are defined by the ratio $X_{c} / w$ and two values ( 0.25 and 0.5 , respectively) are included in the study.

The load-deflection curves obtained by the parametric study are presented in Fig. 6 . And the decreasing ratios of the capacity of glulam columns are presented in the figure, which are calculated by dividing the decrease of capacity caused by the cracks to the capacity of initially perfect columns. In the format legend A-B-C-D, A indicates the column length; B represents the crack pattern included in columns, where TC stands for columns with through cracks; $\mathrm{C}$ stands for the ratios

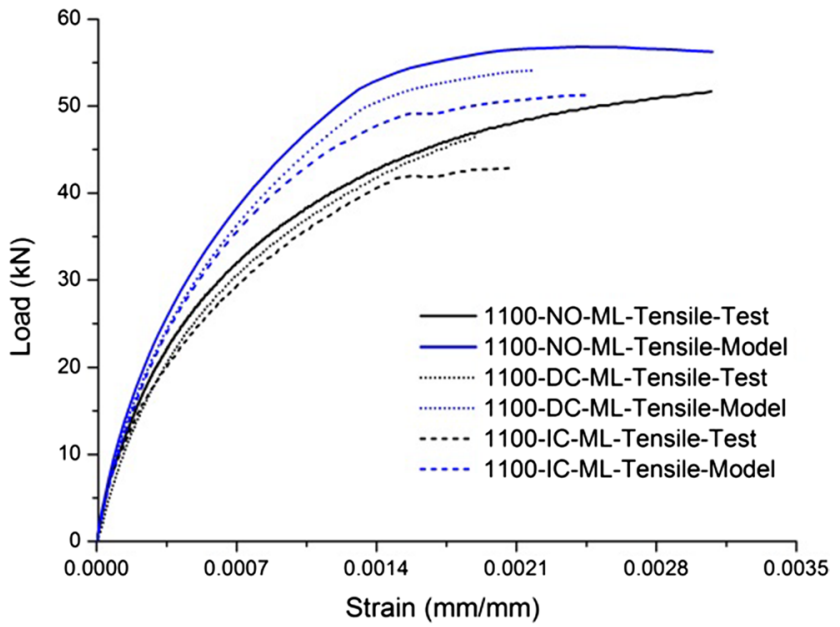

(b)

lam columns with length of $600 \mathrm{~mm}$; b load and longitudinal strain of glulam columns with length of $1100 \mathrm{~mm}$ 


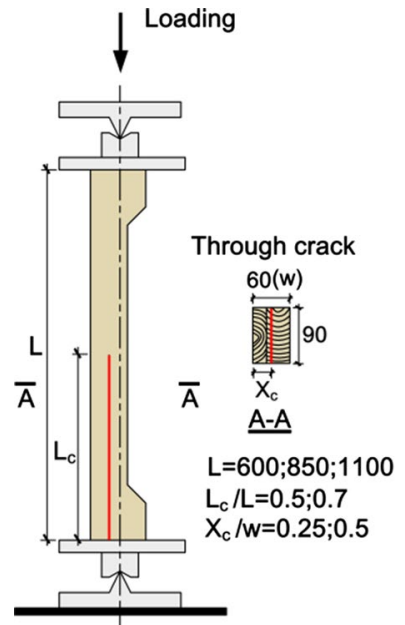

(a)

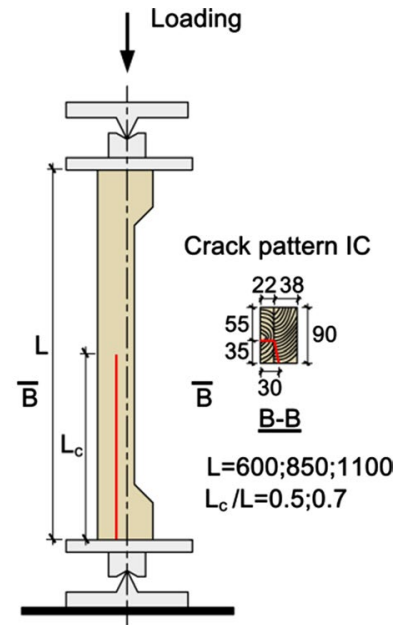

(b)
Fig. 5 The configurations of glulam columns considered in the analysis a columns with through crack; b columns with crack pattern IC

of crack length to the column length; and $\mathrm{D}$ indicates the locations of the through cracks by the ratio $X_{c} / w$, as defined in Fig. 5. As can be seen from Fig. 6, crack pattern IC has more significant influence on the capacity of glulam columns with larger slenderness ratio. When the crack length ratio increases to be 0.7 , the crack can reduce the capacity of columns with length of $1100 \mathrm{~mm}$ by $12.2 \%$. In terms of through crack, for columns with length of $600 \mathrm{~mm}$, the crack set on the center line has less significant effect on the capacity of columns than that set on one side with the ratio $X_{\mathrm{c}} / w$ of 0.25 . The main reason is that the half column separated by through crack on the center carries more compressive load than the small branch divided by the crack set on one side, and due to the larger frictional force induced on the interface between the half column and the bottom steel plate, it is more difficult for the half column to slide and relieve the compressive load than the small branch. The decreasing ratio of capacity can be up to $24.8 \%$, which is caused by the crack set on one side with crack length ratio of 0.7 , as can be seen from Fig. 6a. However, for columns with length of 850 , the decreasing ratios of the capacity caused by through crack set at two different locations are quite similar to each other. The maximum decreasing ratios of capacity caused by cracks set on the center and on one side are 29.3 and $33.1 \%$, respectively, as shown in Fig. 6b. For columns with length of $1100 \mathrm{~mm}$, the influence of through crack set on the center is more significant than the crack set on one side, which is quite different from columns with length of 600 and $850 \mathrm{~mm}$. The main reason for the difference among columns with three kinds of lengths is that in specimens with larger slenderness ratio, less compressive load is carried by the half column separated by the center through crack, and both the half column and the small branch divided by the crack set on one side are able to slide and lose contact with the steel plate.

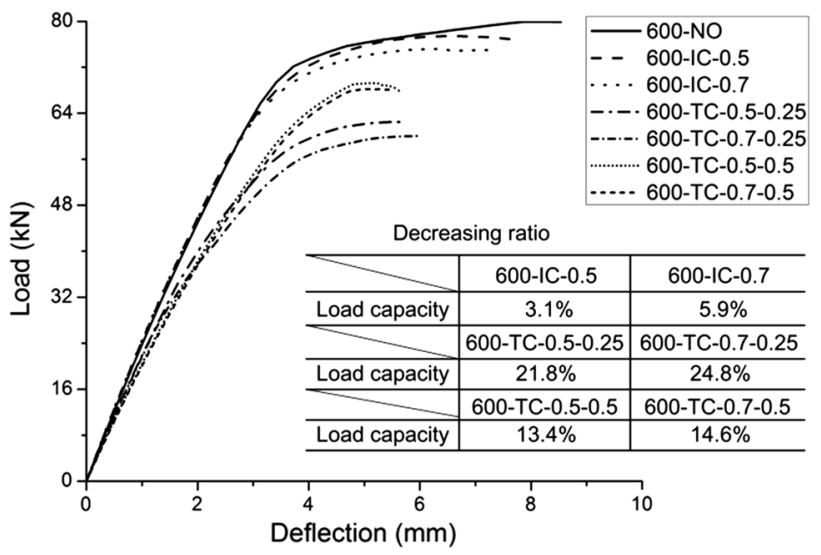

(a)

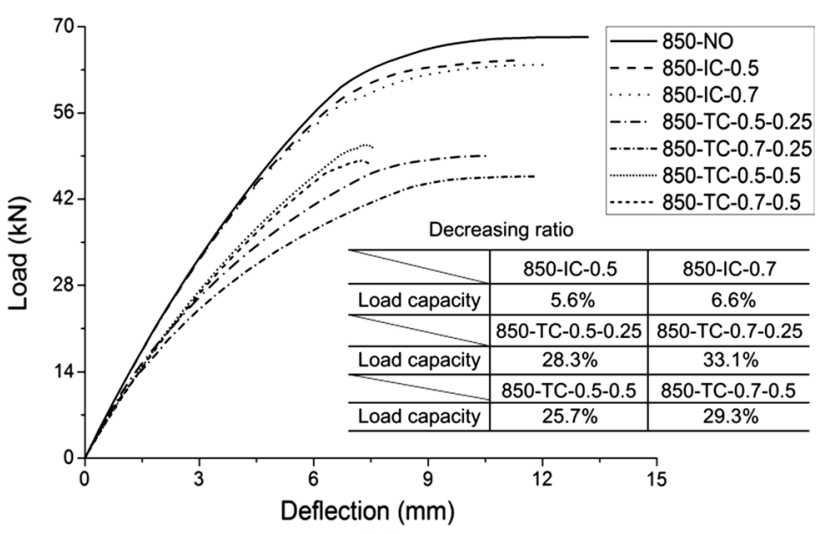

(b)

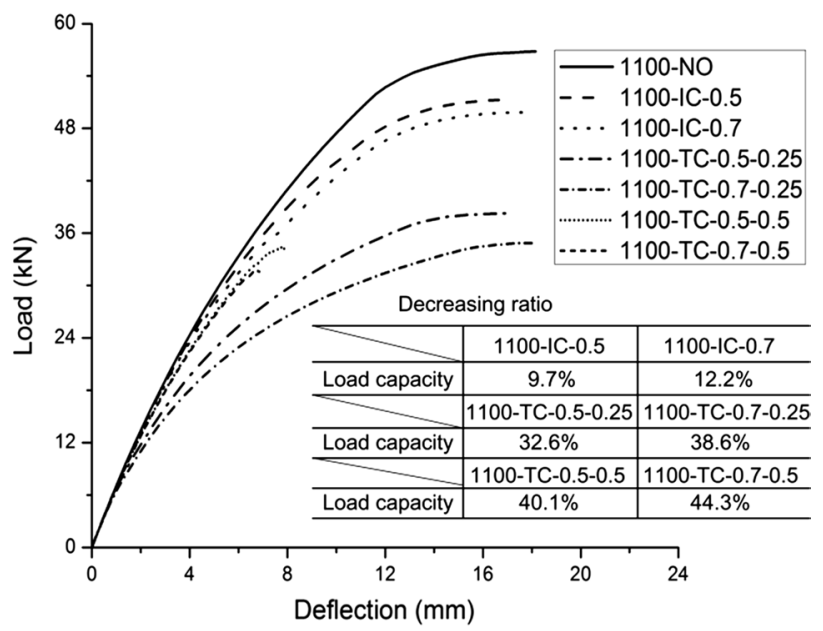

(c)

Fig. 6 The load-deflection curves of glulam columns considered in the analysis a columns with length of $600 \mathrm{~mm}$; b columns with length of $850 \mathrm{~mm}$; c columns with length of $1100 \mathrm{~mm}$

As can be seen from Fig. 6c, the deflection at the peak point is quite small for columns with center through crack and at this point, the capacity of columns experiences a sudden decrease due to the sliding of the half column. And the decreasing ratios of capacity caused by cracks on the center and on one side can 
be up to 44.3 and $38.6 \%$, respectively, as observed in Fig. 6c. From Fig. 6a-c, it can be seen that through cracks have more dramatic effect on the capacity of columns compared to crack pattern IC. However, both for through crack and crack pattern IC, more significant influence of cracks is observed on columns with larger slenderness ratio, and different crack lengths have similar influence on the capacity of columns. Through cracks at different locations affect the capacity of columns differently, which are related to the slenderness ratios of columns.

\section{Conclusions}

This paper experimentally investigated the influence of initial cracks on the mechanical behavior of glulam columns under eccentric compression loads and two different crack patterns and column lengths were considered. Further, a numerical model was developed and a parametric study was conducted to explore the influence of different crack lengths and crack locations after validating the model by test results. The conclusions can be drawn as follows:

1. Initial cracks have more significant influence on the capacity of glulam columns with larger slenderness ratio. For columns with length of $1100 \mathrm{~mm}$, its capacity was reduced by up to 9.9 and $16.6 \%$ due to the existence of crack patterns DC and IC, respectively.

2. Compared to crack patterns DC and IC, through cracks have more dramatic influence on the capacity of glulam columns and the cracks affected the behavior of slender columns more dramatically. For columns with length of $1100 \mathrm{~mm}$, the decreasing ratio of the capacity can be up to $44.3 \%$ due to the existence of through crack on the center line.

3. The effects of through cracks set at different locations are related to the slenderness ratios of columns. The cracks set on the center line reduce the capacity of slenderer columns more significantly; while through cracks set on one side have more dramatic influence on the columns with small slenderness ratio.

4. Initial cracks with different lengths have similar influence on the capacity of columns. When crack length ratio switches from 0.5 to 0.7 , no obvious rise is observed in the decreasing ratios of column's capacity.

Acknowledgements The authors gratefully acknowledge National Key R\&D Program of China (Grant no. 2016YFC0701603) for supporting this research.

Open Access This article is distributed under the terms of the Creative Commons Attribution 4.0 International License (http://creativecomm ons.org/licenses/by/4.0/), which permits unrestricted use, distribution, and reproduction in any medium, provided you give appropriate credit to the original author(s) and the source, provide a link to the Creative Commons license, and indicate if changes were made.

\section{References}

AITC-American institute of timber construction (2011) Evaluation of checks in structural glued laminated timbers", Technical Note 18, Centennial, Colorado, US

APA-The Engineered Wood Association and Engineered Wood Systems (2006) Owner's guide to understanding checks in glued laminated timber", EWS F450, Tacoma, Washington, US

APA-The Engineered Wood Association and Engineered Wood Systems (2007) Evaluation of check size in glued laminated timber beams", EWS R475E, Tacoma, Washington, US,

Berg S, Sandberg D, Ekevad M, Vaziri M (2015) Crack influence on load-bearing capacity of glued laminated timber using extended finite element modelling. Wood Mater Sci Eng 10(4):335-343

Blyberg L (2008) Modelling the effect of cracks in an inverted double-tapered glulam beam", Master's thesis, School of Mathematics and System Engineering, Växjö University, Sweden

Coureau JL, Morel S, Gustafsson PJ, Lespine C (2007) Influence of the fracture softening behaviour of wood on load-COD curve and R-curve. Mater Struct 40(1):97-106

Danielsson H, Gustafsson PJ (2011) A probabilistic fracture mechanics method and strength analysis of glulam beams with holes. Eur J Wood Wood Prod 69(3):407-419

De Moura M, Silva M, De Morais A, Morais J (2006) Equivalent crack based mode II fracture characterization of wood. Eng Fract Mech 73(8):978-993

Dourado N, Morel S, de Moura MFSF, Valentin G, Morais J (2008) Comparison of fracture properties of two wood species through cohesive crack simulations. Compos A Appl Sci Manuf 39(2):415-427

Fragiacomo M, Fortino S, Tononi D, Usardi I, Toratti T (2011) Moisture-induced stresses perpendicular to grain in cross-sections of timber members exposed to different climates. Eng Struct 33(11):3071-3078

Franke B, Quenneville P (2011) Numerical modeling of the failure behavior of dowel connections in wood. J Eng Mech 137(3):186-195

Frühwald Hansson E, Serrano E, Toratti T, Emilsson A, Thelandersson S (2007) Design of safe timber structures-how can we learn from structural failures in concrete, steel and timber. Report TVBK-3053. Lund Institute of Technology, Sweden

Gustafsson PJ (2002) Mean stress approach and initial crack approach-Fracture mechanics models for analysis of timber beams with a hole or a notch-a report of RILEM TC-133. Report TVSM-7134, Lund University, Sweden

He MJ, Zhang J, Li Z (2016) Compressive behaviour of timber columns with longitudinal cracks. In: 2016 World Conference on Timber Engineering, WCTE 2016. 2016, Vienna University of Technology, Vienna

He MJ, Zhang J, Li Z (2017) Influence of cracks on the mechanical performance of dowel type glulam bolted joints. Constr Build Mater 153:445-458

Khorasan SR (2012) Finite-element simulations of glulam beams with natural cracks, Master's Degree Thesis, Department of Mechanical Engineering, Blekinge Institute of Technology, Karlskrona, Sweden

Larsen F, Ormarsson S (2013) Numerical and experimental study of moisture-induced stress and strain field developments in timber logs. Wood Sci Technol 47(4):837-852 
Oliveira J, De Moura M, Silva M, Morais J (2007) Numerical analysis of the MMB test for mixed-mode I/II wood fracture. Compos Sci Technol 67(9):1764-1771

Pop O, Dubois F, Absi J (2013) J-integral evaluation in cracked wood specimen using the mark tracking method. Wood Sci Technol 47(2):257-267

Pousette A, Ekevad M (2012) Shear resistance of glulam beams with cracks, CIB-W18/45-12-5. Working Commission W18-Timber Structures, pp 27-30

Saracoglu E (2011) Finite-element simulations of the influence of cracks on the strength of glulam beams", Master's Degree Thesis, Department of Mechanical Engineering, Blekinge Institute of Technology, Karlskrona, Sweden

Serrano E, Gustafsson PJ (2007) Fracture mechanics in timber engineering__ strength analyses of components and joints. Mater Struct 40(1):87-96

Sjödin J (2006) Steel-to-timber dowel joints: Influence of moisture induced stresses, Licentiate thesis, School of Technology and Design, Växjö University, Sweden

Sjödin J (2008) Strength and moisture aspects of steel-timber dowel joints in glulam structures", Doctoral thesis, School of Technology and Design, Växjö University, Sweden

Sjödin J, Johansson CJ, Petersson H (2004) Influence of moisture induced stresses in steel-to-timber dowel joints. In: Proceedings of the 8th world conference on timber engineering WCTE 2004. Lahti, Finland

Sjödin J, Johansson CJ (2006) Influence of initial moisture induced stresses in multiple steel-to-timber dowel joints. Holz Roh- Werkst 65(1):71-77

Sjödin J, Serrano E (2006) A numerical study of the effects of stresses induced by moisture gradients in steel-timber dowel joints, Holzforschung 60(6)

Sjödin J, Serrano E (2008) An experimental study of the effects of moisture variations and gradients in the joint area in steel-timber dowel joints. Holzforschung 62(2):243-247

Yoshihara H (2008) Theoretical analysis of 4-ENF tests for mode II fracturing in wood by finite element method. Eng Fract Mech 75(2):290-296

Zhang W, Song X, Gu X, Tang H (2012) Compressive behavior of longitudinally cracked timber columns retrofitted using FRP sheets. Struct Eng 138(1):90-98

Publisher's Note Springer Nature remains neutral with regard to urisdictional claims in published maps and institutional affiliations. 